\title{
Encontros e imaginações compartilhadas: lições sobre o que pode o queer*
}

Flavia do Bonsucesso Teixeira**

Queer in the Tropics: Gender and Sexuality in the Global South, de Pedro Paulo Gomes Pereira, é apresentado pelo autor como um livro-experiência. São vidas e teorias que tecem trajetórias $e(m)$ afetos. Pedro Paulo vai incorporando seus encontros com experiências-outras, e aqui o uso do gerúndio se faz necessário, posto que o movimento e o devir são constituintes de um caminhar que segue abalando as teorias que viajaram aos trópicos, ao Sul Global. O livro constrói uma análise que, a partir da teoria queer, convida à interpelação da configuração sexo/gênero como parte do projeto colonial.

Ensaio passos entre mundos e teorias, daqui do interior, com um olhar caipira de quem desconfia de muita coisa: o encontro com o livro me afetou de modo a querer contar umas histórias com Pedro Paulo. Mas, no meio do caminho tinha uma pedra ${ }^{1}$. Não bastasse Richard Miskolci ter escrito a apresentação, Judith Butler escrevera o prefácio do livro. Para que eu adentraria nessa prosa?

Por que esse seria um livro diferente e não só mais uma etnografia sobre as travestis que lutam por acesso aos serviços de

\footnotetext{
* Recebida em 27 de janeiro de 2020, aceita em 28 de abril de 2020. Resenha de Pereira, Pedro Paulo Gomes. Queer in the Tropics: Gender and Sexuality in the Global South. Cham Switzerland, Springer, 2019.

** Professora adjunta da Faculdade de Medicina da Universidade Federal de Uberlândia, Uberlândia, MG, Brasil. https://orcid.org/0000-0001-5605-636X

${ }^{1}$ Utilizo o fragmento do Poema de Carlos Drummond de Andrade para pensar a pedra como acontecimento-problema que integra o percurso.
} 
saúde e outros espaços? E o livro te captura, entre histórias de relacionamentos intensos, de transformação mútua, de tradução cultural e práticas coletivas. Pedro Paulo também problematiza tanto a potência da teoria queer como seus possíveis limites. Rascunhando um novo mapa do possível, ele questiona se estaríamos diante de mais uma teoria do centro que viaja para as periferias para ser aplicada.

Com habilidade, ele desenovela fios teóricos. Entrecruzando as principais abordagens sobre o conceito de biopoder, vai além de analisar as políticas que incentivam e buscam potencializar a vida e pessoas excluídas e deixadas para morrer. $\mathrm{O}$ autor desafia ao questionar a possibilidade de o gesto político queer abrir-se para saberes-outros ou de escaparmos de um pensamento que não permite alterações.

Nesse sentido, o livro demonstra a potência do queer decolonial em não apenas repetir mantras acadêmicos $e$ a possibilidade de ruptura com o aparato e a lógica da colonialidade envolvida em diferentes quadros teóricos fixos que descem do Norte Global para moldar os corpos, as vidas e os saberes do Sul. É um convite para desafiar as teorias, alterar os conceitos $e$ transformá-los, de forma que possam abarcar mais e de forma diferente.

Enfim, Queer in the Tropics fala de traduções, de conversas e de indagações. É desse conjunto de coisas não terminadas que parti para pensar as espirais e pontos de contatos que o livro me (ins)pira e convida a compartilhar imaginações poéticas.

O primeiro texto do Pedro Paulo que conheci foi "Olhos de Medusa: AIDS, terror e poder", sua tese de doutoramento, posteriormente publicada em livro, $O$ terror e a dádiva (Pereira, 2004). O livro possibilitava uma reflexão refinada ao interrogar, de dentro dos muros da instituição, a política de atenção do sistema público de saúde brasileiro, que então se anunciava como a "melhor do mundo" na resposta à epidemia de aids. Cada palavra me afetava porque eu estava no interior de Minas Gerais e compartilhava do mesmo campo, pois a instituição narrada na experiência que Pedro Paulo analisara em Brasília havia surgido 
em Minas Gerais. Assim, eu conhecia algumas das personagens de sua teia de relações, então sua tese e, depois, seu livro, me afetavam de modo singular. Juntos tentávamos compreender o que surgia dessa tensão entre, por um lado, o Estado, com sua ausência mortal no cotidiano de uma instituição total e presença destacada na política e organismos internacionais e, por outro, as ações médico-terapêuticas para portadores de aids.

Se naquela época Pedro Paulo traçava as linhas que conectavam a luta por um sistema de saúde universal, integral $e$ igualitário $e$ as lutas contra a epidemia de aids, na tessitura das lutas pela democratização, nos textos que compõem Queer in the tropics não foi diferente (Pereira, 2019). Dando corpo ao conceito de equidade, ele desnuda a precariedade com que os conceitos de determinantes sociais de saúde e vulnerabilidade são pasteurizados no cotidiano das travestis e demonstra como a democracia é um campo em disputa. Abjeção recebe matéria, contornos de silicone, que a fragilidade de um discurso sobre direitos humanos esvaziado não consegue afetar. Aqui também eu me encontro com Pedro Paulo.

No fazer cotidiano do mundo do trabalho, Pedro Paulo e eu estamos inseridos na tarefa de contribuir para a formação dos estudantes da graduação nas áreas da saúde. Compartilhamos também dessa experiência da tradução entre as áreas. Assim, ao nos envolvermos com a Biomedicina deparamo-nos e tentamos lidar com termos como abjeção/risco/estigma $e$ vulnerabilidade/precariedade, além de temas como $\mathrm{HSH}-$ conceito epidemiológico que cristaliza a prática sexual desvinculada das discussões sobre desejos e sexualidades. Como enfrentar essa máquina que vai homogeneizando conceitos até fazê-los dizer pouco? Considerando que essa seria uma formação necessária ao cuidado em saúde, ou seja, problematizar com os estudantes abjeção, inteligibilidade e borramento sexo/gênero.

Pedro Paulo é personagem navegante na travessia da teoria queer ao Sul. No entanto, em meio à máquina de reproduzir teorias canônicas divididas em departamentos (e campos disciplinares), em saberes institucionalizados, ele nos provoca a 
torcer, a (re)torcer, a enroscar (n)essa estranha-teoria, de modo a (re)fazer sentidos, inclusive para estudantes/profissionais da área de saúde.

Esses sujeitos são inseridos na rede de trânsito das travestis, em momentos de maior fragilidade delas - muitas vezes quando os recursos alternativos se mostraram insuficientes para lidar com a dor -, sendo que pouco ou nada conhecem sobre elas $e$ desconhecem sobre o que vou falar aqui.

Diferentes itinerários terapêuticos conduzirão as travestis aos serviços de saúde, como descobriu Pedro Paulo ao orientar Martha Souza. No entanto, o profissional de saúde, ao chegar supostamente preparado para atendê-las - ainda que as pesquisas demonstrem que o acesso das travestis ao sistema de saúde é precário e marcado por violências -, possui um mapa de viagem que se rende ao suposto preparo humanista (Sharma, Pinto, Kumagai, 2018). Pedro Paulo, então, convida a contorcer os instrumentos-linguagens de um cuidado em saúde que permanece atrelado a um modelo excludente de família, de sociabilidade e de sexo/gênero, que não encontra sentido no modo de vida delas. Foi esse convite que me instigou a imaginação.

A título de incentivar a imaginação poética, invento uma cena em que uma travesti chegaria para ser atendida na Estratégia da Saúde da Família. A cena não aconteceu, mas poderia ter acontecido. Ainda que esse serviço fosse orientado pela Política Nacional de Humanização e seus profissionais trabalhassem na perspectiva da Clínica Ampliada, as travestis e seus modos de vida não caberiam nos seus instrumentos.

$\mathrm{Na}$ perspectiva de compreender o processo de funcionamento e interação da família, o preenchimento do Genograma $^{2}$ seria uma demanda aparentemente simples, mas se transformaria, para muitas delas, em um tempo de constrangimento.

\footnotetext{
2 Para uma aproximação ao uso dos instrumentos Genograma e Ecomapa na área da saúde, no Brasil, sugiro a leitura da revisão integrativa realizada por Lucila Nascimento e colaboradores (2014).
} 
Afinal, a família, tomada como conceito universal $e$ traduzida para os instrumentos na lógica da heteronormatividade, reafirma a abjeção das travestis. Como representar, na lógica binária de um quadrado ou círculo, um sujeito cuja subjetividade insiste em escapar?

Como Cilene, interlocutora de Pedro Paulo e que surge em um dos capítulos de Queer in the tropics, contaria algo de sua experiência como funcionária da rodoviária de Santa Maria, limpando os banheiros, tanto o feminino quanto o masculino, pois como ela diz, "eu sou as duas coisas" (Pereira, 2019:61). A impossibilidade de um serviço como Estratégia da Saúde da Família representar Cilene é de uma literalidade dura: ela é impensável para o campo da saúde. Campo que segue ostentando orgulhosamente que gênero e sexualidade integram os Determinantes Sociais em Saúde.

Se esse profissional da saúde buscasse apoio em evidências para essa abordagem, encontraria a orientação sobre a representação gráfica de corpos dissidentes na qual a pessoa homossexual deveria ser representada por meio de um triângulo invertido colocado no interior do símbolo (quadrado ou círculo), a depender do gênero atribuído ao nascimento (Muniz, Eisenstein, 2009).

A associação entre o triângulo $e$ a homossexualidade preso na estrutura de outra figura geométrica parece aliviar o terror que a ideia de linhas de fuga traria aos saberes que são orientados pela norma heterossexual. Mas também desconsidera o terror dos campos de concentração, onde os triângulos rosa indicavam a vida nua dos homossexuais.

No caso das travestis, podemos falar de corpos-homem $e$ corpos-mulher que não se atrelam à biologia e se reinventam, fazendo questionar se são adequados os termos homem-mulher, alocados em justaposição ao vocábulo corpo, questionando a vinculação direta de gênero e sexualidade. De qualquer forma que se pense esse contexto, parece bem claro que existe uma procura insistente por gramáticas diferentes de corpos e sexualidades. Como, então, tornar inteligíveis corpos dissidentes, que não 
encontram léxico na gramática da anatomia? Como, então, encontrar no queer um arejamento em relação a um modo de perscrutar o corpo e escutar no sujeito a ressonância da heteronormatividade? Como reapresentar esses corposexperiências sem marcá-los como exceção?

Também seria preciso repensar, em outras famílias, outras formas de traduzir e fixar, mesmo que momentaneamente, as experiências-vidas-corpos das travestis.

De família bem humilde, Cilene viu-se obrigada a sair cedo da escola, tanto pelas violências cotidianas de colegas, direcionadas ao então "menino afeminado", como por ter sido abusada sexualmente pelo psicólogo da escola. Sua transformação corporal também não se deu tranquilamente. A família não a aceitou e ela sofreu com as condenações $e$ castigos, especialmente de seu pai. Em meio a relações conflituosas, com as quais não conseguia lidar, não teve outra opção que sair de casa para "morar com outras travestis" (Pereira, 2019:59).

E a cena etnográfica inventada por mim, mas que parte das histórias de tantas travestis brasileiras narradas em primeira ou terceira pessoas em diferentes pesquisas, encontros ou mesmo conversas paralelas. Como Cilene teria suas linhas de relacionamento traçadas pelo profissional de saúde?

As linhas se transformam em rede de impossibilidades gráfica pela superposição de violências, isolamento e conflitos familiares nas trajetórias das travestis. Os nós entre as linhas que tento explicar, quando digo do processo de sujeição que naturaliza a violência no imaginário das travestis, são lidos e se leem ao desenhá-las como pessoas sem direitos. A violência participa das tecnologias de produção da subjetividade.

Um olhar atento para o Genograma como dispositivo diria sua impossibilidade de aplicação, considerando as famílias como ensinou Mariza Corrêa (1993). Mas se o convite do livro é para alterar os conceitos, transformá-los de forma que possam abarcar mais e diferente, insisto que novos símbolos e linhas devem ser 
inventados para fazer ler, tornar matéria, incorporar as vidas dissidentes.

A "vida na rua" de Cilene, segundo ela, não fora diferente da de outras travestis de Santa Maria com as quais convivia: surras, brigas, drogas, bebidas alcoólicas, ferimentos, cicatrizes, roubos, investigações da polícia, além das insistentes pressões das "donas da quadra". Buscava redes de apoio, sobretudo com outras travestis. Fez uso de hormônios, tomando as injeções na mesma esquina onde fazia "ponto"; colocou silicone nos seios tardiamente com uma "bombadeira" conhecida e tem cicatrizes deste episódio denunciado pelas "amarrações" - como se as cicatrizes também atuassem na construção de seu corpo. Por problemas de saúde, "saiu da quadra" em 2010. (Pereira, 2019:60)

Ao mesmo tempo em que Pedro Paulo nos convida para uma "descida ao cotidiano" (Das, 2007) de Cilene, ele mostra que essa descida ao cotidiano do cuidado em saúde produzido no encontro com os profissionais de saúde também é um movimento a ser construído.

Pedro também nos apresenta Morgana. Travesti de 46 anos, mãe de santo e nascida de Santa Maria. Ela vive com sua "família de santo". Na casa, moram apenas pessoas que são "da religião" - seu marido e seus filhos de santo. Tornou-se mãe de santo em 2014, mas diz que foi "da religião quase a vida inteira". Tendo sido criada pelo seu pai de santo, a única família que conheceu foi a família de santo (Pereira, 2019:81).

$\mathrm{O}$ que pode dizer o Genograma de Morgana? Recolocando a questão, perguntaria: quais profissionais da saúde se aventurariam a redesenhar um Genograma para que as linhas e os tracejados da experiência de afetos de Morgana reapresentassem uma família?

Impossível; desnecessário; sem justificativa; seriam as respostas mais convincentes. Provavelmente uma breve anotação sobre a ausência de informações sobre vínculos familiares seria a 
sentença proferida sobre a Morgana selaria o não (querer) saber dos profissionais de saúde (Paulino, Rasera, Teixeira, 2019).

Construída ancorada no binarismo, a arquitetura dos instrumentos não consegue enquadrar as travestis. No entanto, ao atuar como engrenagens do dispositivo de produção de gêneros, antes de advertir sobre suas falhas e limites, eles seguem excluindo e marcando aquelas que não consegue alcançar plenamente.

Seguindo o traçado proposto por Pedro Paulo, penso nas linhas das quais se expandem as famílias, mas também redesenham outras sociabilidades que escapam ao instituído. Ele fabrica torções, rompe e recupera teorias, produzindo fissuras no aparato e na lógica da colonialidade ao percorrer os terreiros em Santa Maria e as quadras de Brasília.

Quem observasse Eduardo naquela caminhada, naquele itinerário torto, poderia ver uma "vida nua", relegada à própria sorte. Mas ele, apesar da penúria, era mais. Eduardo havia achado um entre que minha etnografia, vale repetir, concentrada que foi em instituições, não pode acompanhar. Essa invenção de um entre precário possível o fazia escapar, escorregar, escorrer. Nesses itinerários, Eduardo não era apenas alvo de terapias medicamentosas, nem exclusivamente objeto de um poder médico que tudo controla, nem era só a "sucata do mundo" depositada num refúgio para portadores de aids, nem somente uma vida desnuda a exibir sua precariedade e irrelevância numa paisagem social já por demais saturada, tampouco simples produto da agência de um sistema imunitário que quer se precaver do contágio e da poluição dos seres abjetos. Sendo, talvez, tudo isso, ele era mais. Um mais que o fez escapar naquele dia, conformando minha última imagem dele: andando pelas ruas, errando pelo seu intricado $e$ imprevisível itinerário. "Aonde você vai Eduardo?", indaguei. "Vou para onde minhas pernas forem, errando por esse mundão de meu Deus!", repetiu. E sorriu. (Pereira, 2019:20) 
Sigo persistindo nesse itinerário errante entre os escritos de Pedro Paulo $e$ as análises dos instrumentos que reiteram a impossibilidade das vidas travestis se mantidos presos nas molduras teóricas que foram produzidos. Como parte de cuidado centrado no usuário, é comum o uso do Ecomapa para identificar as redes de relações dos sujeitos que buscam os serviços de saúde, pensando em rede de apoio e interação. Novamente temos a neblina dos Determinantes Sociais em Saúde rondando nossas maneiras de ler o mundo. Ao informar que frequentariam as casas de santo em Santa Maria, como representariam os profissionais de saúde?

Pedro Paulo demonstra que religião não é um indicador ou uma categoria sociodemográfica apenas; os entes sobrenaturais seriam para as travestis de Santa Maria tão mediadores quanto a biotecnologia.

As travestis se definiriam por atos, gestos corporais $e$ discursos; por próteses cibernéticas e substâncias químicas, mas também, e sobretudo, por santos e entidades. Os corpos das travestis seriam diferentes, pois produzidos por outros mediadores e conformados (e conformando) por outras subjetividades - os corpos hormonizados $e$ siliconados precisam ser "trabalhados no batuque", como já havia me ensinado Cida. (Pereira, 2019:42)

As casas de santo não são locais frequentados pelas travestis, são espaços de fabricação de um modo travesti que talvez só faça sentido no interior de Santa Maria.

Pedro Paulo demonstra que não há como separar corpos abjetos, sexualidades dissidentes, de localização geográfica, língua, história e cultura. Como o profissional de saúde teria registrado a perambulação de Cilene pelas esquinas da prostituição onde se encontram o lícito, o ilícito, o dizível e o impronunciável das relações? Seus trânsitos entre terreiro, peruqueiras e bombadeiras, considerados essenciais no processo de sua invenção? O autor, mais do que simplesmente afirmar, demonstra como a teoria queer é também uma política de localização. Queer e pensamento 
decolonial são teorias corporificadas que expandem conceitos $e$ forçam deslocamentos. Quais dos eventos seriam considerados críticos na história de Cida: a relação sexual, aos 12 anos, com o médico que lhe administrava hormônios, ou sua expulsão de casa a partir do corpo que muda?

Esse médico percebeu que aquele "menino era diferente" $e$ passou a efetuar práticas que mudaram o corpo de Cida. Segundo ela, "Ele [o médico] começou a me bolinar. Ficava sozinho comigo e começava a fazer as coisas. Foi me dando remédio e meus peitinhos começaram a crescer. Eu tinha doze anos quando fiz amor com ele. " A partir daí seu corpo foi se alterando a tal ponto que se viu obrigada a mudar do interior de Minas, dirigindo-se, inicialmente, para Belo Horizonte. (Pereira, 2019:35)

Quais mediadores do biopoder seriam recuperados na (re)interpretação médica da história pregressa de Cida? Uma criança abusada por (com) hormônios? Vítima de tráfico internacional de pessoas ou migrante em busca de poder? Cida se fez entre Minas e Europa em uma narrativa-movimento de vai, volta e enlaça que não deixa capturar-se como vítima e nem mesmo como heroína.

A habilidosa tradução das histórias recontadas no livro exemplifica a delicada tarefa de desconstruir a lógica $e$ o aparato eurocêntricos demonstrando seu substrato particular, local e, como diz o próprio autor, provincial.

\section{Referências bibliográficas}

CORREAA, Mariza. Repensando a família patriarcal brasileira: notas para o estudo das formas de organização familiar no Brasil. In: CORRÊA, M. (Org.). Colcha de retalhos: estudos sobre a família no Brasil. 2. ed. Campinas, Editora da Unicamp, 1993.

DAS, Veena. Life and words: violence and the descent into the ordinary. Berkeley, University of California Press, 2007. 
MUNIZ, José Roberto; EISENSTEIN, Evelyn. Genograma: informações sobre família na (in)formação médica. Rev. bras. educ. Med (33). Rio de Janeiro, Mar. 2009, pp.72-79. DOI: 10.1590/S010055022009000100010. Acesso em: 10 de out. 2020.

NASCIMENTO, Lucila Castanheira et al. Genograma e ecomapa: contribuições da enfermagem brasileira. Texto contexto - enferm (23). Florianópolis, mar. 2014, pp.211-220. DOI: 10.1590/S010055022009000100010. Acesso em: 10 de out. 2020.

PAULINO, D. B.; RASERA, E. F.; TEIXEIRA, F. B. Discursos sobre o cuidado em saúde de Lésbicas, Gays, Bissexuais, Travestis, Transexuais (LGBT) entre médicas(os) da Estratégia Saúde da Familia. Interface (23). Botucatu, 2019, pp.1-15. DOI: 10.1590/interface.180279, Acesso em: 10 de out. 2020.

PEREIRA, Pedro Paulo Gomes. Queer in the Tropics: Gender and Sexuality in the Global South. Cham Switzerland, Springer, 2019.

PEREIRA, Pedro Paulo Gomes. O terror e a dádiva. Goiânia-Brasília, Editoras Cânone e Vieira, 2004.

PISCITELLI, Adriana; LOWENKRON, Laura. Categorias em movimento: a gestão de vítimas do tráfico de pessoas na Espanha e no Brasil. Cienc. Cult (67). São Paulo, Jun. 2015, pp.35-39. DOI: 10.21800/2317-66602015000200012. Acesso em 27 de jan.2019

SHARMA, M.; PINTO, A. D.; KUMAGAI, A. K. Teaching the social determinants of health: a path to equity or a road to nowhere? Acad Med (93). Jan. 2018, pp.25-30. DOI: 10.1097/ACM.0000000000001689. Acesso em: 27 de jan. 2019. 